\title{
Arbor
}

\section{El estudio de caso como informe biográfico-narrativo}

\section{Antonio Bolivar Botía}

Arbor CLXXI, 675 (Marzo), 559-578 pp.

La investigación biográfica y narrativa se ha constituido en un enfoque propio de investigación. Este artículo, además de resaltar la dimensión narrativa de los informes de estudios de caso, hace una revisión actual de la literatura sobre la metodología de análisis narrativo de relatos biográficos, como base para la elaboración del informe, que es -a su vezuna forma particular de relato, para no perder dicho carácter narrativo. Las críticas a los tratamientos categoriales o analíticos están reclamando una mayor narratividad en los informes de investigación, que cuestionan los formatos habituales (tipo APA).

El informe de investigación tradicional, en el que se enuncia el problema, se revisa la bibliografía, se diseña, se recogen datos, se analiza y se concluye, es especialmente inadecuado como informe de un estudio de caso [...] El informe puede parecerse a una historia. [...] Gran parte de los datos que recogemos de otras personas estarán en forma de historias que éstas cuentan, y gran parte de lo que transmitamos a nuestros lectores conservará esta forma.

Robert Stake (1998)

\section{Introducción}

Los estudios de caso y la investigación biográfico-narrativa comparten, desde su origen como metodología de investigación social (Escuela de Chicago), ser enfoques hermenéuticos, alternativos a formas positivistas, 
donde las «vivencias» (que decía Ortega siguiendo a Dilthey) o el «mundo de la vida» (Husserl) recuperan un papel relevante en la investigación. Aquel volumen monográfico que Thomas y Znaniecki dedicaban al relato de vida del campesino polaco Wladek emigrado a Chicago en las primeras décadas del pasado siglo, se considera, en este sentido, conjuntamente como un estudio de caso y una investigación biográfico-narrativa ejemplar. Pensamos, como aseveraban entonces Thomas y Znaniecki (1998, p. 45), que la personalidad humana constituye una base de la explicación causal de los acontecimientos sociales, en una interacción continua entre la conciencia individual y la realidad social objetiva.

La investigación biográfica (desde la life-history) y, especialmente, narrativa (narrative inquiry) se han constituido, tras la crisis del positivismo y el giro hermenéutico en ciencias sociales, en un enfoque específico de investigación con su propia credibilidad, que reclama -como hemos defendido (Bolívar, Domingo y Fernández, 2001) - un modo distintivo del paradigma cualitativo convencional. Se trata de otorgar toda su relevancia a la dimensión discursiva de la individualidad, a los modos como los humanos vivencian y dan significado a su mundo mediante el lenguaje. En su momento, Geertz (1994) definió la cultura como «un ensamble de textos, ellos mismo ensambles, que el antropólogo trata de leer sobre los hombros de aquellos a quienes éstos pertenecen propiamente». Los datos del campo son, entonces, textos a interpretar (interpretandum) por medio de otro texto (interpretans), que en el fondo es el informe de investigación.

En los estudios de caso, frecuentemente lidiamos con historias que la gente nos cuenta sobre cómo «experiencian» unos hechos o contextos y, para comprenderlos, nos vemos obligados a contarlos por medio de informes narrativos. Narrativas de gentes y narrativas del investigador, fenómenos y método se funden, prociuctivamente, para comprender la realidad social. Para Donald Polkinghorne (1998) el relato narrativo (story) es «el esquema fundamental para conjuntar las acciones humanas individuales y acontecimientos en aspectos interrelacionados por medio de una composición comprensible». Como reconstrucción de la experiencia, que da significado a lo sucedido o vivido, requiere como elementos de su configuración, trama argumental, secuencia temporal, personaje/s, y situación.

El diseño, el trabajo empírico de recogida de datos sobre el terreno, el posterior análisis e interpretación, abocan a que el estudio de caso se configure en un informe. El investigador se convierte en aquel que construye y cuenta la historia (researcher-storyteller) por medio de un relato. La tarea investigadora consiste en observar los acontecimientos y personas, 


\section{El estudio de caso como informe biográfico-narrativo}

solicitando que los agentes cuenten sus propias historias y trayectorias acerca de los hechos/acciones solicitados por el investigador $\mathrm{y}$, a partir de su análisis e interpretación, construir nuevas historias/relatos, que serán leídas por el público lector. La investigación narrativa es un proceso, complejo y reflexivo, de mutación de los textos del campo a los textos para el lector. El investigador recrea los textos, de modo que el lector pueda «experienciar» las vidas o acontecimientos narrados. Vivir y revivir, contar y recontar historias forma, pues, parte del trabajo, en un proceso de dar significado a la experiencia.

Enmarcamos y revisamos, en primer lugar, la relación entre estudio de caso y narrativa, para concentrarnos en cómo construir el relato y presentar el estudio de caso, es decir, contar la historia investigada. Xavier Coller (2000), en un buen trabajo español sobre el tema, con un criterio acorde con el que defendemos aquí, identifica el informe con la narración del caso. En el texto inicial Robert Stake sitúa lo que queremos tratar en este trabajo: inadecuación de formas convencionales de elaborar el informe de caso y un enfoque más congruente como narrativa. Pero, por eso mismo, la elaboración del informe es dependiente de la metodología de análisis narrativo de relatos biográficos, sobre la que apuntaremos algunas notas.

Especialmente nos concentramos en estudios de caso descriptivos con un fuerte componente cualitativo en su diseño y metodología, por otra (biográfico), que versan sobre casos individuales o grupales. Hay, sin embargo, muchos estudios de caso analíticos que emplean -con predominio o no- metodologías cuantitativas (especialmente, encuestas y análisis estadísticos). No obstante, por la argumentación que desarrollamos, también en este metodología, en alguna medida el Informe debe tener una dimensión narrativa (Abbott, 1992), no tanto biográfica. La lógica de demostración e inferencia de hipótesis se apoya, en ambos casos, en la argumentación desarrollada.

\section{El estudio de caso y la investigación biográfico-narrativa}

Un estudio de caso, al buscar la comprensión de un hecho, suceso, individuo o grupo en su singularidad, más que una explicación causal por una generalización, suele adquirir -tanto en su proceso de investigación como en el informe- la forma de una investigación biográfico-narrativa. Por su parte, la investigación biográfico-narrativa se focaliza igualmente en casos ejemplares o singulares, y se configura como estudio de caso en la medida en que pretende desvelar un contexto de vida (individual o grupal) específico. Una gran parte de los estudios de caso versan sobre 
hechos donde la dimensión biográfica es clave, importando el propio desarrollo dinámico de la trayectoria seguida. Este aspecto temporal (pasado, presente y futuro), junto con la necesaria trama argumental (foco y dinámica) sobre el contexto, es lo que acerca al Informe de caso a una narrativa biográfica.

Por eso mismo, se concentra en los procesos y dimensiones in situ de la vida, buscando una comprensión «densa» del sentido que le otorgan los participantes a las experiencias y contextos en que están inmersos. Tres espacios dimensionales constituyen una narrativa (en el doble sentido de fenómeno y método): temporal, equilibrio entre personal y social, y espacio o situación (Clandinin y Connelly, 2000), que deben ser trabajadas en el informe.

Los estudios de caso, en el enfoque interpretativo o cualitativo que tratamos, suelen compartir con la investigación narrativa, entre otros, estos caracteres:

- Hermenéutica: Se interesa por los significados, que son interpretados a partir de la observación y la voz (narración) de los agentes/actores. Se intentan conocer los hechos humanos a través de la experiencia humana, tal y como ha sido vivenciada.

- Naturalista: Captar las realidades y acciones en la forma en que se presentan o suceden. La investigación biográfica, como los estudios de caso, se dirige a las situaciones particulares, individuos o eventos en su singularidad. Se busca comprender los valores, creencias y significados de las personas que están inmersas en la situación analizada.

- La selección de personas o grupos es deliberada, no aleatoria o probalística, de tamaño reducido. No se pretende la generalización, cuanto la comprensión, por lo que importa que los sujetos seleccionados puedan incrementarla.

- Dimensión temporal. La narrativa se relaciona específicamente con la comprensión humana del tiempo. Paul Ricoeur ha llegado a afirmar que: el tiempo se hace tiempo humano en la medida en que se articula en un modo narrativo, y la narración alcanza su plena significación cuando se convierte en una condición de la existencia temporal (1995, I).

- El diseño es flexible y emergente, adaptado a las condiciones, normalmente cambiantes, en las que suele darse proceso investigador. Así, los casos pueden ser determinados por «bola de nieve» 0 «en cadena», según avanza la investigación.

- El proceso de investigación suele emplear gran inversión de tiempo en los escenarios naturales, con un contacto directo con los partici- 
pantes. Una parte importante de la información proviene de la observación directa de lo que pasa (eventos/hechos), importándonos principalmente cómo son vividos por las personas/agentes (entrevistas, otras técnicas discursivas o narrativas).

Importa recoger todos los datos y voces que contribuyan a proveer una descripción holística del acontecimiento, situación, persona o grupo. En ocasiones, el estudio de caso vendrá dado por un solo informante, en otros, se podrá tomar el grupo como verdadero sujeto de estudio, dentro del cual, el sujeto y su relato individual adquieren un sentido contextualizado. Como producto o informe de investigación, un estudio de caso es -genéricamente - un relato narrativo, que -como tal- presenta determinados hechos con su propia trama narrativa (comienzo, desarrollo y conclusión o final).

\section{El estudio de caso como informe}

Los estudios de caso arrastran una ambigüedad inicial, pudiéndose referir (Merriam, 1998; Rangin y Becker, 1992) conjuntamente al objeto de estudio, al proceso, o al producto-informe:

a) La unidad objeto de estudio. Desde esta perspectiva el estudio de caso no es una opción metodológica, sino la elección de un objeto, acotado como unidad singular, con unas fronteras claras ("puedo cercar lo que voy a estudiar», dice Merriam, 1998); pudiendo ser investigado de diversas formas (cuantitativas o cualitativas). Ha sido, entre otros, Stake $(1994,1998)$ uno de los que más ardientemente ha defendido que un caso viene definido por la delimitación de una unidad de estudio (con sus propios límites, forma un sistema con partes relacionadas), que puede ser individualizada o singularizada, por lo que se puede comprender dicho caso sin necesidad de recurrir a otros. Desde esta perspectiva, de cualquier objeto de naturaleza social puede construirse en caso, a condición de que sea relevante y de que por naturaleza (no artificial) cumpla dicha unidad (Coller, 2000).

b) El proceso por el que se lleva a cabo la investigación. Consiste primariamente en un modo de investigar, con sus propias reglas y procesos en la recogida y análisis de datos. En este segundo sentido lo define Yin (1987, p. 23) como «una investigación empírica que estudia un fenómeno actual dentro de su contexto de vida real, especialmente cuando los límites entre el fenómeno y el contexto no son evidentes, y que suele requerir el uso de múltiples fuentes de evidencia».

c) El informe de investigación. Una investigación, presentada como estudio de caso, vendría configurada como una descripción profunda (mi- 
nuciosa y exhaustiva) y un análisis sistemático e intensivo de un determinado objeto de estudio, en modos que puedan poner al lector en situación de lo que el investigador ha aprendido en el campo. Así dice Merrian (1998, p. 27): «una descripción y análisis sistémico e intensivo de un determinado ejemplar, fenómeno o entidad».

De ahí la ambigüedad, además de lo que pueda ser «caso» como unidad delimitada, del término "estudio», que puede referirse tanto al proceso de aprendizaje o investigación, como al resultado o producto de dicho estudio. Puede ser una unidad empírica o un constructo teórico. Algo similar acontece a la narrativa: puede ser el «fenómeno» investigado (relatos, acontecimientos o textos escritos o hablados), el «método» empleado para construir o analizar dichos relatos, y -en tercer lugar- el «uso» que se puede hacer del producto de la investigación con diferentes fines. Fenómeno investigado, proceso de investigación y resultado de la misma, conjuntamente adquieren la forma de relato. A su vez, la «historia de vida» se puede referir conjuntamente a la historia vivida por un sujeto, como a escritura o narración de modo autobiográfico o reconstruida por el biógrafo-investigador.

El estudio de caso, en el tercer sentido, como producto o resultado, presenta una información detallada y precisa sobre un sujeto o grupo, elaborado mediante formas biográficas-narrativas; para lo cual frecuentemente, además de la descripción de los contextos, suele recoger voces de los mismos sujetos. Desde un enfoque «microscópico», se pretende desvelar los dispositivos que gobiernan la vida cotidiana de las gentes, mediante las vivencias y curso temporal de los individuos en situaciones específicas.

Podemos distinguir tres tipos fundamentales de estrategia para el diseño de la investigación biográfico-narrativa: estudios de caso con relatos únicos, múltiples, o paralelos. En el primero, como estudio de caso intrínseco que dice Stake, deseamos comprender mejor un caso particular, donde un único individuo o grupo elabora su autobiografía que, como tal, es objeto de investigación, sin pretender ilustrar un problema más general. En los relatos múltiples, varios relatos de vida de personas del mismo entorno son cruzados para comprender, a varias voces (polifónico), la misma historia. Por último, los distintas voces pueden ser puestas en paralelo en torno a cada tema, para ampliar el conocimiento del tema de interés.

\section{Caracteres del informe de investigación como narrativa}

Una buena investigación narrativa no es sólo aquella que recoge bien las distintas voces sobre el terreno, o las interpreta, sino también aque- 


\section{El estudio de caso como informe biográfico-narrativo}

lla que da lugar a una buena historia narrativa, que es -en el fondo- el informe de investigación. Desde esta perspectiva, lo que en la investigación convencional se llama "explicación», no sería más que la mejor forma en que se organiza un relato para que sea comprensible y convincente. Lo biográfico singular se tiene que inscribir en un marco de estructura general, las narrativas de acción en una genealogía de contexto que las expliquen. Como de la etnografía ha dicho Geertz (1994, p. 89) es preciso lograr «un continuo equilibrio dialéctico entre lo más local del detalle local y lo más global de la estructura global de un modo tal que podamos formularlos en una concepción simultánea..., situar a ambas partes en un contexto en el que se expliquen mutuamente».

En un excelente trabajo, Andrew Abbott (1992) critica las prácticas convencionales de confrontar la dicotomía de población (con amplios $\mathrm{N}$ de muestra) versus «estudio de caso» (con uno o varios sujetos), con la dicotomía de "análisis causal» versus «relato narrativo». Argumenta que los científicos sociales, en ambos casos, suelen practicar un análisis narrativo. $\mathrm{Ni}$ los estudios de caso individuales son los que únicamente pueden adoptar un formato narrativo, ni los estudios sobre grandes poblaciones suelen ser sólo «analíticos». Basándose en algunas investigaciones realizadas sobre grandes poblaciones también la narrativa suele ser la fuente última de explicación. La oposición entre población/caso y enfoque analítico/narrativo, bien examinada, no se sostiene: «La diferencia entre un enfoque a la población y al caso no es lo mismo que la diferencia entre enfoques analíticos y narrativos». Generalizaciones pueden ser hechas, con la misma legitimidad, a partir de múltiples casos y no sólo con el lenguaje de variables.

El informe es siempre una recreación de la narración del/os informante/s, por lo que el investigador, practicando un cierto «arte del bricolaje», debe unir las diferentes piezas de modo que otorguen un significado, si es posible ampliándolo. Elaborar el informe es montar un cierto rompecabezas, cuyas piezas no están ya dadas, han debido ser determinadas en el análisis. A través de un marco interpretativo nos orientamos para organizar los datos, reuniendo las más parecidas por un lado; las más dispares, por otro; y -finalmente- identificando las líneas de relación establecidas, que hagan coherente el cuadro dibujado del rompecabezas inicial.

Contar la historia en la elaboración del informe se puede hacer de muchas formas o géneros. Van Manen (1988) habla de que puede haber hasta siete estilos de presentación: realista, impresionista, confesional, crítico, formal, literario, o una conjunción de los anteriores. El informe convencional (tipo aconsejado por la Asociación de Psicología America- 
na), con un marco teórico donde se enuncia el problema y revisa la bibliografía, se formulan las hipótesis, el diseño y procedimiento seguido, datos, resultados y conclusiones o implicaciones; como señalaba Stake, suele imponer un marco forzado en que no encaja la investigación propiamente narrativa.

Cuando desaparece el carácter narrativo en el informe, por un fuerte tratamiento categorial o analítico, la investigación ha dejado de ser narrativa. En cualquier caso, tampoco cabe limitarse a ordenar los textos recogidos. Entre uno y otro extremo se juega un buen informe de investigación. Como dice Huberman (1998, p. 225), «trabajar con biografías actualiza agudamente el intrínseco dilema de hacer investigación en ciencias sociales. El material fuente, el relato de la vida de las personas, es tan múltiple pero al mismo tiempo tan singular que tenemos la impresión de estar deteriorándolo desde el momento mismo en que ponemos sobre ese material nuestras manos descriptivas y analíticas».

El informe de una investigación narrativa debe, entonces, ser él mismo narrativo. Como señala Zeller (1998, p. 296), «paradójicamente, si bien muchos investigadores en las ciencias humanas han rechazado una concepción positivista de la objetividad en la metodología de la investigación, no han rechazado su influencia sobre el estilo de redacción", muy pegados a los modos convencionalmente establecidos. Para eso propone que en la forma de presentación se podría aprender mucho de la nueva etnografía, el nuevo periodismo y de los relatos creativos de ficción y no ficción (por ejemplo, novelas de realismo social). Así, las estrategias narrativas empleadas por los periodistas más innovadores pueden servir de modelo para la redacción de los informes de casos.

\section{Representar los datos de la investigación}

Una de las cuestiones básicas académicas actualmente es cómo realizar la hazaña mágica de transformar los contenidos de la conciencia en formas públicas que otros puedan comprender. El presupuesto de que el lenguaje de las ciencias sociales -lenguaje proposicional y números - son los agentes exclusivos de significado, de modo creciente está llegando a ser problemático y, como resultado, estamos explorando el potencial de otras formas de representación para iluminar el mundo educativo que deseamos comprender... el concepto de formas alternativas de representación de los datos presenta una imagen que reconoce la variedad de modos en que nuestra experiencia es codificada (Eisner, 1997, p. 4)

Con la maestría que Eisner tiene en este campo plantea las «promesas y peligros» de formas alternativas de representación de la investiga- 
ción. Y es que es evidente que, desde el final de la modernidad clásica, estamos inmersos en una grave crisis re-presentacional, unida a una propia crisis de legitimación, donde los criterios habituales (validez, generalización, fiabilidad) también han empezado a tambalearse. La investigación biográfico-narrativa incrementa dicha crisis introduciendo una «fisura» entre la experiencia vivida y cómo deba re-presentarse en el discurso de la investigación. Ilustraremos, a modo de pinceladas, algunos ecos y signos de dicha crisis. Como también ha diagnosticado Geertz (1994, p. 14): Renunciar a un intento de explicación de los fenómenos sociales que los entrelace en grandes texturas de causas y efectos para optar por otra que trate de explicarlos situándolos en marcos locales de conocimiento significa sustituir una serie de dificultades bien definidas por otras mal definidas.

Y ese es justamente uno de los problemas de credibilidad de la investigación narrativa. No es posible aplicarle los cánones del modo paradigmático de conocer (por ejemplo, representatividad) a un modo que es distinto, pero prescindir completamente de ellos podría significar relegarla al campo literario. En este dilema nos movemos actualmente, como hemos analizado extensamente en el trabajo citado (Bolívar, Domingo y Fernández, 2001). Más bien, deben ser redefinidos en unos casos, y en otros, introducir nuevos. Precisamente, hace unos años, Elliot Eisner (Eisner et al., 1996) se atrevió a plantear, en un discurso presidencial en la convención anual de la Asociación de Investigación Educativa Americana, si una tesis doctoral escrita en forma de novela deba ser admitida como una investigación. La propia cuestión era ya un síntoma de que el paradigma establecido empezaba a tambalearse.

Más allá de aspectos particulares en este debate, la cuestión última -como ejemplifica la interesante discusión entre Howard Gardner y Elliot Eisner (Eisner et al., 1996)- es si la investigación educativa es un saber disciplinado, y -por tanto- debe hacerse de acuerdo con los patrones de investigación y presentación de las disciplinas. Eisner defiende que, si bien la narrativa novelada no es el mejor vehículo de representación para todos los problemas educativos, puede ser un modo válido en otros, con tal que se base en un trabajo de campo exhaustivo y sistemático. Lo relevante es que sea fruto de una investigación, y ésta no es una clase de la ciencia, sino la ciencia una especie de investigación. Por tanto, si la presentación narrativa es fruto de una investigación seria, no habría especiales problemas en admitir un relato narrativo como informe científico.

Cada comunidad científica tiene sus propios criterios, a menudo implícitos, sobre lo que deba o no ser aceptado como buena investigación. 
Por eso, los informes suelen ser narrados de acuerdo con los cánones de cada comunidad de ciencias sociales. En una bella analogía, Kushner y Norris decían que la Academia se dedica a cuidar los jardines de la verdad, señalando qué flores, y cómo, deben crecer. Si desde el «Discurso del Método» de Descartes, se han impuesto unos modos paradigmáticos, sucesivamente reformulados; con el final de la modernidad, están entrando aguas turbulentas que desestabilizan los formatos establecidos en cada ciencia normal. No obstante, como dice Hunter McEwan (1998, pp. 2378), parece evidente que «la mayor parte de los escritos académicos puede ser considerada un esfuerzo de sofocar el impulso de relatar una narrativa; y a su vez, las pautas de la composición académica tienden a favorecer las escrituras no narrativas sobre los relatos directos [...]. Así, la sofocación de la narrativa en la mayoría de los escritos académicos es algo más que una preferencia estilística: muchas veces es considerada un requisito académico previo y una demostración del ideal científico que identifica la objetividad con la distancia entre el científico y su objeto de estudio».

Construir un informe, como texto narrativo, es realizar una interpretación hermenéutica, donde cada parte adquiere su significado en función del todo, y el informe como totalidad depende -a su vez- del significado de cada parte. El investigador se encuentra situado entre sus experiencias y textos del campo, y su esfuerzo por dar sentido a lo vivido/recogido. La selección de episodios, voces, observaciones, y especialmente su ordenación y conjunción, crean la historia del caso. A pesar de que contamos con algunas reglas para analizar y escribir el informe, es también una tarea artística; parecida al buen periodista que construye una excelente descripción de una realidad a partir de un caso.

Clandinin y Connelly (2000) se refieren a la tensión inherente en el investigador enfrascado en la tarea de escribir un informe, situado entre las experiencias vividas y su inevitable reducción en un texto. En esta situación, el investigador debe lidiar entre tratamientos formales o reduccionistas y la recogida fiel de las palabras de las gentes como si fueran transparentes por sí mismas. Las experiencias vividas o las historias contadas, en cualquier caso, precisan de una «transformación» desde el plano personal al informe público. La forma ortodoxa (reducción a lenguaje proposicional y tablas numéricas) se está cuestionando crecientemente. Como ha dicho también Geertz (1994), «ciento quince años de prosa aseverativa e inocencia literaria son ya suficientes».

Acudir a formas alternativas de representación (más fuertemente narrativas, en modos literarios y experimentales de escribir historias, hasta llegar a la ficción), como se aduce desde el postestructuralismo, no deja de 
ser problemático. ¿Cuáles son las formas válidas (es decir, aceptadas) de presentación? Es una decisión que depende, como señalaba, en último extremo, de las que son admitidas por una comunidad científica. En cualquier caso, una cosa es evidente: reducir cuantitativamente las dimensiones cualitativas de la experiencia ha empezado a tornarse problemático.

Cualquier forma de representación alternativa puede ser empleada, dice Eisner (1997), con tal que pongan en escena mejor la experiencia e incrementen la comprensión. Algunas formas alternativas de representación tienen, entre otras, estas ventajas:

a) Proveen un sentido de particularidad (carácter individual, cualidades distintivas, autenticidad) que las abstracciones impiden.

b) El material presentado en estas formas alternativas suele ser más evocativo que denotativo, al presentarlo en un texto más abierto a múltiples interpretaciones, lo que le aporta una "ambigüedad productiva».

c) Los nuevos modos de representación amplían nuestros modos de ver y de abordar los problemas, incrementando las cuestiones que podemos responder.

d) Los modos cualitativos de representación posibilitan, en mayor grado que los cuantitativos, la creatividad del investigador y sus cualidades individuales.

Sin embargo, también tienen sus peligros. Si el objetivo de las ciencias sociales convencionales era reducir la ambigüedad e incrementar la precisión, algunas de estas formas alternativas no proveen precisión. Y si bien la ambigüedad puede ser productiva, también da lugar al «síndrome de Rorschach»: cada uno puede conferir un significado idiosincrático a los datos, impidiendo un cierto consenso. Nos importa, además, cómo el informe presentado es usado, para lo que es preciso proporcionar un amplio contexto en el que se sitúa el caso.

\section{El informe entre el análisis, la narración y la persuasión}

El informe narrativo de estudio de caso, aun cuando emplee los mismos datos, puede tener un carácter preferentemente descriptivo, interpretativo o evaluativo; explicativo o analítico (Polkinghorne, 1998; Merriam, 1998):

a) Descriptivo: Proporciona una descripción precisa y exhaustiva de los relatos que los individuos o grupos hacen de los acontecimientos de sus vidas o de los contextos en que trabajan. Esta amplia descripción puede ser base de una interpretación, apoyando presupuestos teóricos previos o, incluso, elaborando construcciones generales. Igualmente, si 
junto a la descripción, se valora y enjuicia la situación (por ejemplo un programa social), el informe será evaluativo.

b) Explicativo: En su uso explicativo, el interés se dirige a establecer una conexión entre los acontecimientos, acumulando aquellos relatos necesarios que puedan justificar tales conexiones. Se tratará de confirmar hipótesis previas, aportando todos aquellos elementos que contribuyan a clarificar los supuestos de partida.

En cualquier caso, en función del análisis de datos practicado, es un tema debatido si los informes deben adoptar un formato analítico, donde se desplieguen las relaciones entre las categorías como si fueran variables; o un informe no formalizado, propiamente narrativo, en una tarea cercana a la descripción literaria o buenos reportajes periodísticos. En fin, como esbozaremos, el problema metodológico en la investigación biográfico-narrativa es cómo combinar, de modo productivo, un estilo más analítico (etic) con otro descriptivo (más emic).

Una cosa es la lógica de descubrimiento o investigación y otra la de exposición y justificación, aunque estén relacionadas. Es preciso combinar y recomponer los diversos datos en modos que puedan proporcionar una comprensión viva y densa. Los informes de investigación están compuestos de narrativas, integrados de datos observacionales, relatos que los informantes cuentan, relatos del investigador, y los modelos teóricos (que -a su vez- son estructuras narrativas) que guían la investigación. Una forma convencional de elaborarlo es partir de explicitar el problema a investigar, destacando su relevancia, surgimiento, teorías previas, posibles hipótesis, etc. A continuación, se pasaría a la justificación de elección y construcción del caso, seguido de la metodología empleada en la recogida de datos, el análisis y modos de interpretación practicados y -finalmente- las conclusiones e implicaciones

Sharan Merriam (1988) sugiere siete marcos analíticos para organizar y presentar los datos: El papel de los participantes, el análisis conjunto de intercambios formales e informales entre los grupos, histórico, temático, recursos, rituales y simbolismo, e incidentes críticos que cambian o refuerzan las creencias fundamentales, prácticas y valores.

Los investigadores sociales podemos aprender a escribir informes de campos cercanos, como el llamado «nuevo periodismo» o periodismo literario, que combina la investigación con la buena escritura. Como señala Zeller (1998, p. 298): «las estrategias de redacción y las técnicas empleadas por los nuevos periodistas parecerían constituir modelos apropiados para los investigadores de caso». Tom Wolfe propuso la definición del nuevo periodismo como la aplicación de técnicas de ficción realista al periodismo. Por ejemplo, la reconstrucción del evento por la representación 
El estudio de caso como informe biográfico-narrativo

de escena tras escena, la incorporación de diálogo, «meterse» dentro de la psicología del personaje y reflejar todos los elementos del ambiente, después de hacer varias «entrevistas a profundidad» a todos los involucrados.

El problema implícito que suscita el nuevo periodismo es la relación entre los datos empíricos (la idea de la veracidad, lo factual, lo empírico) y la técnica narrativa, pues la objetividad es una convención establecida en el campo. Pero, al igual que en nuestro tema, planteó abiertamente que el paradigma del periodismo tradicional que se conduce por las preguntas básicas de ¿quién?, ¿qué?, ¿dónde?, ¿cuándo?, y ¿por qué?, para simular la objetividad, debía ser cuestionado. Los hechos no hablan por sí mismos, son de hecho una construcción. El reportaje es un modo de narrar y percibir los eventos, que necesariamente no se puede identificar con los acontecimientos.

Los múltiples evidencias presentadas y la trama desarrollada en el discurso, a través de estudios de caso, deben -en último extremo- persuadir (Zeller, 1998). Las posibles objeciones que puede suscitar la persuasión deben ser situadas. Tomamos el término, de acuerdo con la «nueva retórica», no en un sentido peyorativo (manipular, argumentos artificiosos), sino como una forma de argumentación «razonable», con argumentos motivados que convenzan de lo que se describe. En una buena distinción, Perelman y Olbrechts-Tyteca (1989, p. 67) llaman persuasiva a «la argumentación que sólo pretende servir para un auditorio particular, y nominalmente convincente a la que se supone que obtiene la adhesión de todo ente de razón», es decir, a un posible «auditorio universal». La persuasión induce a la acción, convencer es una operación intelectual. De este modo, queda definido el discurso convincente, como «aquel en el que las premisas y los argumentos son universalizables, es decir, aceptables, en principio, para todos los miembros del auditorio universal».

$\mathrm{El}$ informe, pues, debe buscar la eficacia de las palabras, conjuntado con los argumentos y voces que lo justifiquen. Como señala Xavier Coller (2000. p. 96), el informe o narración «es el medio a través del cual se intenta convencer al público de la veracidad de las conclusiones del estudio». La argumentación se hace, pues, en función del auditorio al que se dirige; empleando aquellos medios discursivos que puedan convencer de su realidad o veracidad. Si desde esta interpretación actual de la retórica, «toda argumentación se desarrolla en función del auditorio»; todo texto, si desea ser eficaz, debe estar condicionado en su escritura y presentación por el auditorio potencial al que va dirigido, para que pueda provocar su procesamiento social y adhesión. Co- 
mo el propio Eisner (1998, p. 57) afirma: «la indagación cualitativa, como las aproximaciones a la investigación cuantitativa convencional, es en última instancia una materia de persuasión, de ver las cosas de una manera que satisface, o es útil para los propósitos que nos señalamos».

De este modo, las estrategias narrativas desplegadas en el Informe de Investigación buscan provocar la adhesión o asentimiento de los lectores al discurso desarrollado. Estos serán percibidos y entendidos, junto a los argumentos, datos y voces recogidas, en función de cómo se presentan y logran persuadir. «La calidad y la utilidad de la investigación no dependen -dice Stake (1998, p. 115)- de su capacidad de ser reproducida, sino del valor de los significados que han generado el investigador o el lector».

\section{El dilema entre el análisis categorial y la narración}

En el voluminoso informe sobre La miseria del mundo, Pierre Bourdieu y su equipo (1999) privilegian el testimonio oral hasta el punto de renunciar a realizar cualquier tipo de análisis (categorial o no) del amplio material biográfico-narrativo recogido. Se limitan a ordenar y titular de modo coherente la transcripción de las 182 entrevistas correspondientes. Así señalan al comienzo: «Entregamos aquí los testimonios que nos dieron hombres y mujeres en relación con sus existencias y la dificultad de vivir. Los organizamos y presentamos con vistas a conseguir que el lector les dirija una mirada tan comprensiva como la que nos imponen y nos permiten otorgarles las exigencias del método científico».

El argumento principal para esta postura es «dar los medios para comprender, es decir tomar las palabras de la gente como son», dejando para el lector -en una especie de «democratización de la postura hermenéutica»- la tarea de análisis y comprensión. Sólo al final del libro se dedica un apartado (titulado "Comprender») a plantear algunos de los presupuestos epistemológicos con los que han operado en la investigación. Los estudios de casos son, así, pequeños relatos de las gentes, debidamente ordenados según características afines por tema o situación de vida. Si bien dice no creer en «la ilusión espontaneista del discurso que habla de sí mismo", y que han operado ya una interpretación al reescribir las entrevistas orales para que sean legibles, asombra que no aparezca ningún tipo de análisis, justo para ser fiel de la mayor manera posible a las voces de la gente. 


\section{El estudio de caso como informe biográfico-narrativo}

Las reacciones que ha suscitado, en el que algunos se han atrevido a acusar la obra de «la miseria de la sociología» o que contradecía formas con las que el propio Bourdieu había trabajado anteriormente, son muestra de la crisis metodológica y de cómo re-presentar las palabras de las gentes en que nos encontramos. Un análisis formalista o fuertemente categorial fragmenta en elementos codificables el discurso, descontextualizándolo. Pero una «fidelidad» extrema al propio discurso, limitaría el análisis a proporcionar otra narrativa de la información recogida, sólo que ahora el discurso se encuentra enhebrado. Las relaciones entre quien informa y analiza la información, creemos, no pueden limitarse a «tomar nota». La tarea es, por una parte, descifrar significativamente los componentes y dimensiones relevantes de las vidas de los sujetos, y -por otra- situar los relatos narrativos en un contexto que contribuya a proveer una estructura en que tome un sentido más amplio. Para que los relatos sean relevantes a propósitos de investigación, deben ser reconstruidos de acuerdo con determinados modos paradigmáticos aceptados de analizar la información.

La obra, también francesa, de Demazière y Dubar (1997) Cómo analizar las entrevistas biográficas es también ejemplificadora de este grave déficit metodológico sobre cómo analizar las entrevistas biográficas, que son discurso narrativo. En ella, si bien hacen una fundamentada crítica de los métodos convencionales de análisis, cuando llegan a proponer como alternativa el análisis estructural de relatos, tipo Barthes, no nos parece una salida definitiva. Rechazan como insuficientes tanto una postura ilustrativa, que se limita a hacer un uso selectivo de las palabras de los entrevistados al servicio de lo que quiere mostrar el investigador, como una postura hiperrealista, que trata de dar todo el valor a las propias palabras de los entrevistados, como si las palabras fueran por sí mismas transparentes. En su lugar, defienden un modo analítico de abordar las entrevistas, con una teoría generada del análisis de los datos, y decidiéndose por un análisis estructural de los relatos biográficos. En este sentido piensan que las diferentes técnicas de análisis de contenido son inadecuadas para analizar las entrevistas biográficas.

En efecto, extraer ad hoc (es decir, descontextualizados) trozos o párrafos que permitan ejemplificar, concretar o ilustrar lo que ya, previamente, se pretende demostrar, no es una posición defendible. Pero tampoco lo es, por el contrario, restituir simplemente las entrevistas en su retranscripción literal, para no «traicionar» la palabra de los sujetos, reduciendo los comentarios al mínimo. Las palabras de los entrevistados no son transparentes, ni hablan por sí mismas. Si se las quiere comprender, es preciso que el investigador las retraduzca y 
analice, por lo que no debe limitarse a ser portador de la palabra de una persona o grupo. Una postura analítica busca producir, de modo metódico, sentido a partir de la explotación de las entrevistas de investigación

Bajo el lema de rechazar las generalizaciones y las posibles distorsiones de la narración de los sujetos, no se puede sacralizar el discurso emic de éstos. Al fin y al cabo, los propios relatos de los profesores son construcciones sociales que dan un determinado significado a los hechos, y que, como tales, deben ser analizados por la investigación. Como comenta Huberman, parece legítimo en la investigación educativa buscar temas y sentidos comunes en las biografías docentes singulares, que nos induzcan posibles explicaciones de por qué dicen lo que dicen. De hecho, esto es lo que han pretendido las ciencias sociales.

La cuestión última es qué estatus se le debe dar a las palabras de la gente o, en otros términos, si lo biográfico es complementario o deba tener autonomía; en cualquier caso cómo re-presentar las voces, en una coyuntura de crisis de la representación. Estas no son transparentes por ellas mismas de la realidad, construyen discursivamente un mundo vivido por los agentes, la entrevista obedece a reglas específicas de producción de sentido. Ni las posturas ilustrativas (extractos de entrevista, citados para ilustrar lo que se dice, en una «apropiación selectiva»), ni en el caso extremo, el textualismo radical (otorgar un gran lugar a la palabra de los entrevistados, restituyendo las palabras como si lo dijeran todo), resultan hoy sostenibles.

Mientras tanto, la salida intermedia de un análisis categorial (con todas las variantes, incluidos programas por ordenador, de análisis de contenido), ha conducido a un cierto desengaño, pues no estamos antes textos informativos, sino ante relatos biográficos que construyen humanamente (sentir, pensar, actuar) una realidad. Se ha reparado poco en que el análisis empírico de contenido categorial surgió inicialmente (Berelson) para el tratamiento de textos informativos o periodísticos, donde la dimensión personal-afectiva está ausente; por ello su aplicación a textos que no describen hechos sino que reconstruyen un mundo/vida en el propio discurso es siempre deficiente, nunca cabe atrapar los matices de la narrativización de una vida bajo una categoría temática. Demazière y Dubar (1997, p. 94) llegan a afirmar que, en el caso de las entrevistas narrativas, «las diferentes técnicas de análisis de contenido son inadecuadas para el análisis de las significaciones que queremos realizar». No obstante, cabe combinar análisis cualitativos y hermenéuticos del contenido, con los propios análisis cuantitativos, en una conjunción 


\section{El estudio de caso como informe biográfico-narrativo}

fructífera, aún cuando un equilibrio sea inestable, presto a romperse por un extremo.

\section{¿Cómo quedamos?}

Hemos dado cuenta de la tendencia en ciencias sociales a «recortar» las voces registradas de los agentes, según el gusto del investigador, manipulando el discurso originario. Actualmente, el asunto se juega en lograr un equilibrio entre una interpretación que no se limite -desde dentro- a los discursos de los entrevistados, ni tampoco una interpretación -desde fuera- que prescinda de los matices y modulaciones del discurso narrado. Superar el mero «collage» de fragmentos de textos mezclados ad hoc, implica que el investigador debe penetrar en el complejo conjunto de símbolos que la gente usa para conferir significado a su mundo y vida, logrando una descripción lo suficientemente rica donde obtengan sentido.

Recurriendo a la metáfora del paisaje, Bruner (1988) decía: «el relato debe construir dos paisajes simultáneamente»: el paisaje exterior de la acción y el paisaje interior del pensamiento y las intenciones. Nos encontraríamos, entonces, en que hay un doble discurso: enunciado de hechos o acontecimientos, y lo que piensa/siente ante ellos. Se evoca el pasado junto a un juicio sobre su vida y presente, lo que suscita la anticipación de futuros posibles. En relación con el primer paisaje, a lo largo de las entrevistas o narraciones biográficas se hacen continuas referencias a acontecimientos externos en relación a los cuales se va inscribiendo la vida. Además de esta función referencial (describe el estado de cómo son las cosas), hay una función modal (lo que se piensa de ellas), e incluso una función de acto (alterar el estado del oyente). Si el primer tipo de discurso, con función referencial, puede ser categorizado; el segundo, más modal, no se deja atrapar con categorías temáticas.

Hay que practicar en la investigación narrativa, entonces, en una especie de visión binocular, una «doble descripción». Por una parte, se necesita un retrato de la realidad interna del informante; por otra, se tiene que inscribir en un contexto externo que aporte significado y sentido a la realidad vivida por el informante. Si hay que situar las experiencias narradas en el discurso dentro de un conjunto de regularidades y pautas explicables sociohistóricamente, pensando que el relato de vida responde a una realidad socialmente construida, sin embargo, no se puede desdeñar que es completamente única y singular. En fin, estamos ante el dilema, ya referido, de conjugar un punto de vista del nativo (emic) y del investigador (etic). En muchas ocasiones, los papeles del cognoscente y conocido 
cambian o, mejor, dejan de diferenciarse para conjuntarse, rompiendo con lo que ha sido un principio intocable de la objetividad cognoscitiva moderna.

Tal como hemos apuntado, actualmente, en nuestra coyuntura posmoderna, el asunto de redacción del informe de estudio de caso se juega entre no sacralizar los relatos, ni tampoco asimilarlos a tradicionales modos paradigmáticos de conocer, en los que vanamente encajarían. En suma, un modo abierto de investigar y relacionarse con las voces de las gentes, aun cuando conjugar ambos extremos -preciso es reconocerlo- no deja de ser en la práctica un equilibrio inestable, presto a romperse en un extremo u otro. En último extremo, estamos ante qué debe contar como investigación, y -por otro- si la investigación debe asimilarse a los modos científicos establecidos. Formas enteramente narrativas, como una buena novela (realista), pueden aportar un grado de conocimiento de una realidad que ya lo podrían reclamar investigaciones cuantitativas. Pero, como investigación, debe tener conjuntamente un formato de argumentación narrativa y apoyarse -con algún grado de sistematicidad- en datos. La forma de presentación (más narrativa o analítica y formalizada) no determina por sí misma su carácter de investigación, sino el modo como argumenta y justifica.

A la hora de elaborar un informe biográfico-narrativo nos encontramos, pues, entre no querer violar/expropiar las voces de los sujetos investigados, imponiéndoles análisis categoriales alejados de las palabras de los sujetos, y someterlos a los cánones formales que nos induzcan a explicar por qué dicen lo que dicen. Nuestro problema es que si respeta en exceso el discurso emic de los actores sociales, la interpretación queda presa dentro de los horizontes de los interpretados (como sería la quimérica etnografía de los trobiandeses hecha por ellos mismos), imposibilitando toda explicación comparativa, generalizable o teórica; lo que torna superflua cualquier tarea de análisis.

Con las especificaciones antes señaladas, abogamos por que -para que dichos relatos sean relevantes a los propósitos de la investigacióndeben también someterse a determinados modos paradigmáticos aceptados de analizar la información. Un «textualismo radical», excluyendo todo tipo de análisis paradigmático, plantea una ruptura con los modos académicos de investigar. En esta coyuntura, por ahora, un marco de inteligibilidad de las narraciones tiene que conjugar aquellos elementos tal y como fueron dichos en descripción emic, y -al tiempo- no renunciar a hacer descripciones interpretativas que vayan más allá de los horizontes de los interpretados. Como ha escrito Geertz (1994, p. 22), de lo que se trata es de: reorganizar las categorías de un modo tal que puedan 


\section{El estudio de caso como informe biográfico-narrativo}

divulgarse más allá de los contextos en los que se gestaron y adquirieron sentido originalmente con el fin de encontrar afinidades y señalar diferencias.

\section{Bibliografía}

Аввот, A. (1992): What do Cases do? Some Notes on Activity in Sociological Analysis. En What is a Case? Exploring the Foundations of Social Inquiry, C. Ragin y H. Becker (Eds.) (pp. 53-82). Nueva York: Cambridge University Press.

Bolívar, A., Domingo, J. y Fernández, M. (2001): La investigación biográfico-narrativa en educación. Enfoque y metodología. Madrid: La Muralla.

Bourdieu, P. (1999): La miseria del mundo. Madrid: Akal.

BRUner, J. (1988): Realidad mental, mundos posibles. Barcelona: Gedisa.

Clandinin, J. y ConNelly, M. (2000): Narrative Inquiry: Experience and Story in Qualitative Research. San Francisco, CA: Jossey-Bass.

Coller, X. (2000): Estudio de casos. (Cuadernos metodológicos, 30). Madrid: C.I.S.

Demazière, D. y Dubar, C. (1997): Analyser les Entretiens Biographiques. Paris: Nathan.

EISNER, E. (1997): The Promise and Perils of Alternative Forms of Data Representation. Educational Researcher 26(6), 4-10.

EISNER, E. W. (1998): El ojo ilustrado. Indagación cualitativa y mejora de la práctica educativa. Barcelona: Paidós.

EISNER, E., GARDNER, H. et. al. (1996): Should Novels Count as Dissertations in Education? Research in the Teaching of English 30(4), 403-427.

Geertz, C. (1994): Conocimiento local. Ensayos sobre la interpretación de las culturas, Barcelona: Paidós.

Huberman, M. (1998): Trabajando con narrativas biográficas. En La narrativa en la enseñanza, el aprendizaje y la investigación, H. McEwan y K. Egan (Comps.) (pp. 183235). Buenos Aires: Amorrortu.

McEwan, H. y EGAN, K. (Comps.) (1998): La narrativa en la enseñanza, el aprendizaje y la investigación. Buenos Aires: Amorrortu.

McEwan, H. (1998): Las narrativas en el estudio de la docencia. En La narrativa en la enseñanza, el aprendizaje y la investigación, H. McEwan y K. Egan (Comps.) (pp. 236259). Buenos Aires: Amorrortu.

Merriam, S. B. (1998): Qualitative Research and Case Study Applications in Education. San Francisco: Jossey-Bass Publs.

Perelman, C. y Olbrechts-Tyteca, P. (1989): La nueva retórica. Teoría de la argumentación. Madrid: Gredos.

Polkinghorne, D. (1988): Narrative Knowing and the Human Sciences. Albany, NY.: State University of New York Press.

Ragin, C. C. y BeCker, H. S. (Eds.) (1992): What is a Case? Exploring the Foundations of Social Inquiry. Nueva York: Cambridge University Press.

RICOUEUR, P. (1995): Tiempo y narración I (configuración del tiempo en el relato histórico); II (configuración del tiempo en el relato de ficción); III (el tiempo narrado). México: Siglo XXI.

Stake, R. E.(1994): Case Studies. En Handbook of Qualitative Research, N.K. Denzin e Y.S. Lincoln (Eds.) (pp. 236-247). Thousand Oaks, CA: Sage. 


\section{Antonio Bolivar Botía}

STAKE, R. E.(1998): Investigación con estudio de casos. Madrid: Morata.

Thomas, W. I. y Znanieckin, F. (1998): Le Paysan Polonais en Europe et en Amérique. Récit de Vie d'un Migrant (Chicago, 1919). Paris: Nathan.

van Manen, J. (1988): Tales of the Field: On Writing Ethnography. Chicago: University of Chicago Press.

YIN, R. K. (1987). Case study research: Design and methods. Newbury Park, CA: Sage.

ZELLER, N. (1998): La racionalidad narrativa en la investigación educativa. En La narrativa en la enseñanza, el aprendizaje y la investigación, $\mathrm{H}$. McEwan y K. Egan (Comps.) (pp. 295-314). Buenos Aires: Amorrortu. 